\title{
Analisis Perilaku Yang Memengaruhi Pemeriksaan ANC Pada Ibu Hamil Di Wilayah Kerja Puskesmas Kebayakan Kabupaten Aceh Tengah Provinsi Aceh Tahun 2019
}

\section{Analysis Of Behaviour ANC Examination Influenced In Maternal In The Working Area Of Kebayakan Health Centre Of Central Aceh District Aceh Province In 2019}

\author{
Khairuni Hikmah*1, Fatma Sylvana Dewi Harahap², Rapida Saragih³ \\ 1,2,3 Institut Kesehatan Helvetia, Jl. Kapten Sumarsono No. 107, Medan 20124
}

\begin{abstract}
*Koresponding Penulis: ${ }^{1}$ khairuni_hikmah@yahoo.com, ${ }^{2}$ fatmaharahap80@gmail.com, ${ }^{3}$ pida81saragih@gmail.com
\end{abstract}
\begin{abstract}
ABSTRAK
World Health Organization (WHO) merekomendasikan bahwa kewajiban kunjungan ANC selama kehamilan normal adalah empat kali kunjungan selama kehamilan dengan standar dan waktu yang telah ditetapkan. Tujuan penelitian ini adalah untuk menganalisis perilaku yang memengaruhi pemeriksaan ANC pada ibu hamil di wilayah kerja Puskesmas Kebayakan Kabupaten Aceh Tengah Provinsi Aceh. Jenis penelitian ini menggunakan Mix Methods dengan strategi metode Eksplanatoris Sekuensial. Populasi berjumlah 411 orang dan sampel sebanyak 80 responden, sedangkan informan kualitatif 2 ibu hamil, 2 suami, 1 bidan dan 1 kepala puskesmas. Analisis data kuantitatif dengan analisis univariat, bivariat dan multivariat. Analisis data kualitatif meliputi reduction, display dan conclusiondrawing/verification. Berdasarkan hasil uji chi-square diperoleh pada variabel umur $p=0,036$, pendidikan $p=0,000$, pekerjaan $\mathrm{p}=0,292$, pengetahuan $\mathrm{p}=0,011$, paritas $\mathrm{p}=0,891$, jarak tempat kesehatan $\mathrm{p}=$ 0,005 , dukungan suami $\mathrm{p}=0,005$. Secara kualitatif penyebab ibu hamil tidak lengkap memeriksakan ANC adalah kurangnya dukungan yang diberikan oleh suami, jarak tempat pelayanan kesehatan yang jauh serta adanya pengalaman kehamilan sebelumnya. Kesimpulan dalam penelitian ini adalah ada pengaruh umur, pendidikan, pengetahuan, jarak tempat kesehatan, dukungan suami terhadap pemeriksaan ANC dan tidak ada pengaruh pekerjaan dan paritas terhadap pemeriksaan ANC di wilayah kerja Puskesmas Kebayakan Kabupaten Aceh Tengah Tahun 2019. Disarankan bagi suami agar memberikan dukungan terhadap ibu hamil dengan cara mengantar, mengingatkan ibu untuk memeriksakan kehamilannya sampai dengan lengkap serta menanyakan hasil dari pemeriksaan kehamilannya.
\end{abstract}

\section{Kata Kunci : Perilaku, Jarak Tempat Kesehatan, Dukungan Suami, Kehamilan, Pemeriksaan ANC}

\begin{abstract}
World Health Organization (WHO) recommends that the obligation to visit ANC during normal pregnancy is four visits during pregnancy with a predetermined standard and time. The purpose of this study was to analyze the behaviors that influence ANC examination in pregnant women in the work area of the District Health Center of Keb Aceh Central Aceh Province. This type of research uses Mix Methods with the Sequential Exploratory method. The population was 411 people and a sample of 80 respondents, while the qualitative informants were 2 pregnant women, 2 husbands, 1 midwife and 1 head of the puskesmas. Quantitative data analysis with univariate, bivariate and multivariate analysis. Qualitative data analysis
\end{abstract}


Journal of Healthcare Technology and Medicine Vol. 6 No. 2 Oktober 2020

Universitas Ubudiyah Indonesia

e-ISSN : 2615-109X

includes reduction, display and conclusion drawing / verification. Based on the results of the chi-square test obtained at the age variable $p=0.036$, education $p=0,000$, occupation $p=$ 0.292 , knowledge $p=0.011$, parity $p=0.891$, distance of health place $p=0.005$, husband support $p=0.005$. Qualitatively the cause of incomplete pregnant women checking ANC is the lack of support provided by the husband, the distance from the place of health care and the experience of previous pregnancy. The conclusion of this study is that there is an influence of age, education, knowledge, distance of health, husband support for ANC examination and no influence of work and parity for ANC examination in the work area of Kebaya Health Center in Central Aceh Regency in 2019. It is recommended for husbands to provide support for pregnant women by way of delivery, reminded mothers to check their pregnancies to the full and ask for the results of pregnancy checks.

\section{Keywords : Behavior, Distance of Health Space, Husband Support, Pregnancy, ANC Examination}

\section{PENDAHULUAN}

World Health Organization (WHO) atau organisasi kesehatan dunia merekomendasikan bahwa kewajiban kunjungan ANC selama kehamilan normal adalah empat kali kunjungan selama kehamilan dengan standar dan waktu yang telah ditetapkan. Menurut data dari WHO 2016 hanya 64\% dari wanita dunia yang melahirkan hidup yang menerima pelayanan ANC empat kali atau lebih. Sedangkan Asia Tenggara sebesar 57\% yang menduduki angka terendah setelah Mediterania Timur (Khasanah, 2017).

Menurut Kemenkes RI 2014, pelayanan ANC minimal 4 kali selama kehamilan dengan jadwal yang telah ditentukan yaitu minimal 1 kali pada trimester pertama (K1), satu kali pada trimester kedua (K2), dan dua kali pada trimester ketiga (K3 dan K4). Kunjungan ANC dengan waktu yang telah ditentukan tersebut bertujuan untuk memberikan perlindungan terhadap ibu hamil dan atau pada janinnya berupa deteksi dini terhadap faktor resiko, pencegahan dan penanganan dini terhadap komplikasi kehamilan (Khasanah, 2017). Beberapa dampak jika ibu tidak teratur dalam melakukan kunjungan ANC, antara lain tidak dapat diketahui kelainankelainan pada ibu dan janin, tidak dapat diketahui faktor-faktor resiko yang mungkin terjadi pada ibu, tidak dapat mendeteksi secara dini penyakit yang diderita pada ibu selama masa hamil (Prawirohardjo, 2010).

Selama tahun 2006 sampai tahun 2017 cakupan pelayanan kesehatan ibu hamil K4 di Indonesia cenderung meningkat. Jika dibandingkan dengan target Rencana Strategis (Renstra) Kementerian Kesehatan tahun 2017 yang sebesar 76\%, capaian tahun 2017 telah mencapai target tahun tersebut walaupun masih terdapat 11 provinsi yang belum mencapai target (Kemenkes RI, 2018). 
Journal of Healthcare Technology and Medicine Vol. 6 No. 2 Oktober 2020

Universitas Ubudiyah Indonesia

e-ISSN : 2615-109X

Cakupan K1 dan K4 di Provinsi Aceh cenderung meningkat dari tahun ke tahun. Untuk tiga tahun terakhir masing-masing yaitu, pada tahun 2015 cakupan $\mathrm{K} 1$ sebesar $86 \%$ dan cakupan K4 sebesar 79\%, tahun 2016 cakupan K1 sebesar 87\% dan cakupan K4 sebesar 78\% dan untuk tahun 2017 cakupan K1 sebesar 91\% dan cakupan K4 sebesar 82\% (Dinkes Aceh, 2018).

Cakupan K1 di Kabupaten Aceh Tengah Tahun 2016 mencapai 89,2\% dan cakupan K4 mencapai 79,5\% telah mencapai target nasional yaitu sebesar 74\%. cakupan K1 yang belum memenuhi target terdapat di Puskesmas Jagong Jeget dan Puskesmas Kebayakan dimana cakupan rendah dibawah $85 \%$. Sedangkan untuk cakupan K4 masih banyak puskesmas yang dibawah 85\%. Hanya Puskesmas Rusip Antara, Celala, Bies, Pegasing, Atu Lintang dan Linge yang mencapai target (Profil Kesehatan Kabupaten Aceh Tengah, 2016).

Cakupan K1 Kabupaten Aceh Tengah Tahun 2017 mencapai 87,5\% dan cakupan K4 mencapai $80 \%$ telah mencapai target nasional yaitu sebesar 76\%. Cakupan K1 yang belum memenuhi target terdapat di Puskesmas Jagong Jeget, Atu Lintang, Lut Tawar dan Puskesmas Kute Panang dimana cakupannya masih rendah yaitu dibawah $85 \%$. Sedangkan untuk cakupan K4 masih banyak puskesmas yang dibawah $85 \%$. Hanya beberapa Puskesmas yang sudah mencapai target (Profil Kesehatan Kabupaten Aceh Tengah, 2017).

Salah satu Puskesmas yang cakupannya masih rendah yaitu dibawah $85 \%$ adalah Puskesmas Kebayakan Kabupaten Aceh Tengah. Berdasarkan data yang diperoleh di Puskemas Kebayakan Kabupaten Aceh Tengah, tahun 2016 sasaran ibu hamil yaitu 362 orang, untuk cakupan K1 sebesar 77\% dan cakupan K4 sebesar 69\%. Sasaran ibu hamil tahun 2017 adalah 421 orang, untuk cakupan K1 sebesar 87\% dan cakupan K4 sebesar 68\%. Selanjutnya pada tahun 2018, sasaran ibu hamil yaitu 411 orang, untuk cakupan K1 sebesar $86 \%$ dan cakupan K4 sebesar 82\%. Sedangkan sasaran ibu hamil tahun 2019 adalah 411 orang, untuk periode Januari cakupan K1 sebesar 8,3\% dan cakupan K4 sebesar 6\%, sedangkan untuk periode Februari cakupan K1 sebesar 18\% dan cakupan K4 sebesar 12\%.

Berdasarkan survei awal yang penulis lakukan diperoleh bahwa dari 5 orang ibu hamil terdapat 2 orang telah memeriksakan kehamilan sebanyak 1 kali hingga kehamilan memasuki tri semester ketiga, hal ini terjadi karena kehamilan adalah hal biasa yang akan dihadapi oleh setiap wanita sehingga tidak perlu dilakukan pemeriksaan khusus, terutama pada ibu yang sudah memiliki lebih dari 2 orang anak, ibu yang bekerja diluar rumah akan menyulitkan untuk menyempatkan waktu melakukan pemeriksaan kehamilan, serta suami juga tidak mendukung 
Journal of Healthcare Technology and Medicine Vol. 6 No. 2 Oktober 2020

Universitas Ubudiyah Indonesia

e-ISSN : 2615-109X

untuk melakukan pemeriksaan kehamilan sejak awal karena ibu dalam kondisi sehat dan kesibukan suami yang tidak bisa menemani ibu dalam pemeriksaan kehamilan.

Sedangkan 2 orang ibu hamil yang dilakukan wawancara menyatakan melakukan pemeriksaan kehamilan dengan lengkap (melakukan kunjungan K-1 dan K-4) selama kehamilannya karena suami dan keluarga yang terus mengingatkan ibu untuk melakukan pemeriksaan kehamilan secara rutin dan tenaga kesehatan yang terus mengingatkan ibu dan keluarga untuk melakukan pemeriksaan kesehatan. Sedangkan seorang ibu hamil mengatakan bahwa ibu mengalami kesulitan untuk melakukan pemeriksaan kehamilan karena jarak rumah ke pelayanan kesehatan yang jauh, serta ibu tidak ada yang mengantar ke pelayanan kesehatan, sehingga ibu harus menggunakan becak untuk bisa sampai ke pelayanan kesehatan.

\section{METODE PENELITIAN}

Jenis penelitian ini menggunakan Mix Methods dengan strategi metode yang akan digunakan yaitu strategi eksplanatoris sekuensial. Pendekatan yang digunakan dalam kuantitatif yaitu cross sectional dan kualitatif menggunakan grounded theory. Penelitian telah dilakukan di Wilayah Kerja Puskesmas Kebayakan Kabupaten Aceh Tengah Provinsi Aceh. Waktu penelitian berlangsung mulai bulan September sampai dengan bulan Oktober tahun 2019.

Adapun populasi dalam penelitian ini adalah seluruh ibu hamil yang ada di wilayah kerja Puskesmas Kebayakan Kabupaten Aceh Tengah Provinsi Aceh Tahun 2019, berjumlah 411 orang. Sampel untuk penelitian kuantitatif diambil secara Nonprobability Sampling dengan sampling purposive yaitu teknik dengan penentuan sampel dengan pertimbangan tertentu. Sampel dalam penelitian ini adalah seluruh ibu hamil trimester 3 yang ada di wilayah kerja Puskesmas Kebayakan Kabupaten Aceh Tengah Provinsi Aceh berjumlah 80 responden. Sedangkan informan untuk pendekatan kualitatif yaitu informan kunci : ibu hamil yang tidak lengkap melakukan pemeriksaan ANC berjumlah 2 informan, dan informan pendukung : suami, bidan dan kepala puskesmas. Data hasil survey dianalisis dengan menggunakan uji chiSquare dan diperkuat dengan penelitian kualitatif guna untuk memperdalam hasil dari penelitan kuantitatif.

\section{HASIL DAN PEMBAHASAN}

\section{Tabel 1}


Distribusi Frekuensi Analisis Perilaku yang Memengaruhi Pemeriksaan ANC Pada Ibu hamil di Wilayah Kerja Puskesmas Kebayakan Kabupaten Aceh Tengah Provinsi Aceh Tahun 2019

\begin{tabular}{|c|c|c|}
\hline Variabel & $\mathbf{F}$ & Persentase \\
\hline \multicolumn{3}{|l|}{ Umur } \\
\hline Beresiko & 19 & 23,7 \\
\hline Tidak Beresiko & 61 & 76,3 \\
\hline \multicolumn{3}{|l|}{ Pendidikan } \\
\hline Dasar & 15 & 18,8 \\
\hline Menengah & 39 & 48,7 \\
\hline Tinggi & 26 & 32,5 \\
\hline \multicolumn{3}{|l|}{ Pekerjaan } \\
\hline Tidak Bekerja & 43 & 53,8 \\
\hline Bekerja & 37 & 46,2 \\
\hline \multicolumn{3}{|l|}{ Pengetahuan } \\
\hline Kurang & 35 & 43,8 \\
\hline Baik & 45 & 56,2 \\
\hline \multicolumn{3}{|l|}{ Paritas } \\
\hline Primipara & 37 & 46,3 \\
\hline Multipara & 43 & 53,7 \\
\hline \multicolumn{3}{|l|}{$\begin{array}{c}\text { Jarak Tempat } \\
\text { Kesehatan } \\
\end{array}$} \\
\hline Jauh & 46 & 57,5 \\
\hline Dekat & 34 & 42,5 \\
\hline \multicolumn{3}{|l|}{ Dukungan Suami } \\
\hline Tidak Mendukung & 36 & 45 \\
\hline Mendukung & 44 & 55 \\
\hline \multicolumn{3}{|l|}{ Pemeriksaan ANC } \\
\hline Tidak Lengkap & 32 & 40 \\
\hline Lengkap & 48 & 60 \\
\hline
\end{tabular}

Sumber : Data Primer, 2019

Berdasarkan tabel di atas dapat dilihat bahwa, perilaku yang memengaruhi pemeriksaan ANC pada ibu hamil mayoritas umur tidak beresiko sebanyak 61 responden (76,3\%), pengaruh pendidikan terhadap pemeriksaan ANC mayoritas pendidikan menengah sebanyak 39 responden $(48,7 \%)$, pengaruh pekerjaan terhadap pemeriksaan ANC mayoritas tidak bekerja sebanyak 43 responden (53,8\%), pengaruh pengetahuan terhadap pemeriksaan ANC mayoritas dengan pengetahuan baik sebanyak 45 responden $(56,2 \%)$, pengaruh paritas terhadap pemeriksaan ANC mayoritas multipara sebanyak 43 responden $(53,7 \%)$, pengaruh jarak tempat kesehatan terhadap pemeriksaan ANC mayoritas dengan jarak yang jauh sebanyak 46 responden $(57,5 \%)$, pengaruh dukungan suami terhadap pemeriksaan ANC mayoritas 
Journal of Healthcare Technology and Medicine Vol. 6 No. 2 Oktober 2020

Universitas Ubudiyah Indonesia

e-ISSN : 2615-109X

mendukung sebanyak 44 responden (55\%) dan pemeriksaan ANC mayoritas lengkap sebanyak 48 responden $(60 \%)$.

Tabel 2

Tabulasi Silang Analisis Perilaku yang Memengaruhi Pemeriksaan ANC Pada Ibu hamil di Wilayah Kerja Puskesmas Kebayakan Kabupaten Aceh Tengah

Provinsi Aceh Tahun 2019

\begin{tabular}{|c|c|c|c|c|c|c|c|}
\hline \multirow{3}{*}{ Variabel } & \multicolumn{4}{|c|}{ Pemeriksaan ANC } & & & \multirow{3}{*}{$P$ value } \\
\hline & \multicolumn{2}{|c|}{ Tidak Lengkap } & \multicolumn{2}{|c|}{ Lengkap } & \multicolumn{2}{|c|}{ Jumlah } & \\
\hline & $\mathbf{F}$ & $\%$ & $\mathbf{F}$ & $\%$ & $\mathbf{F}$ & $\%$ & \\
\hline \multicolumn{8}{|l|}{ Umur } \\
\hline Beresiko & 12 & 15 & 7 & 8,7 & 19 & 23,7 & 0,036 \\
\hline Tidak Beresiko & 20 & 25 & 41 & 51,3 & 61 & 76,3 & \\
\hline Total & 32 & 40 & 48 & 60 & 80 & 100 & \\
\hline \multicolumn{8}{|l|}{ Pendidikan } \\
\hline Dasar & 13 & 16,3 & 2 & 2 & 15 & 18,3 & 0,000 \\
\hline Menengah & 13 & 16,2 & 26 & 33 & 39 & 49,2 & \\
\hline Tinggi & 6 & 7,5 & 20 & 25 & 26 & 32,5 & \\
\hline Total & 32 & 40 & 48 & 60 & 80 & 100 & \\
\hline \multicolumn{8}{|l|}{ Pekerjaan } \\
\hline Tidak Bekerja & 20 & 25 & 23 & 28,8 & 43 & 53,8 & 0,292 \\
\hline Bekerja & 12 & 15 & 25 & 31,2 & 37 & 46,2 & \\
\hline Total & 32 & 40 & 48 & 60 & 80 & 100 & \\
\hline \multicolumn{8}{|l|}{ Pengetahuan } \\
\hline Kurang & 20 & 25 & 15 & 18,8 & 35 & 43,8 & 0,011 \\
\hline Baik & 12 & 15 & 33 & 41,2 & 45 & 56,2 & \\
\hline Total & 32 & 40 & 48 & 60 & 80 & 100 & \\
\hline \multicolumn{8}{|l|}{ Paritas } \\
\hline Primipara & 14 & 17,5 & 23 & 28,8 & 37 & 46,3 & 0,891 \\
\hline Multipara & 18 & 22,5 & 25 & 31,2 & 43 & 53,7 & \\
\hline Total & 32 & 40 & 48 & 60 & 80 & 100 & \\
\hline \multicolumn{8}{|l|}{$\begin{array}{c}\text { Jarak Tempat } \\
\text { Kesehatan }\end{array}$} \\
\hline Jauh & 25 & 31,3 & 21 & 26,3 & 46 & 57,6 & 0,005 \\
\hline Dekat & 7 & 8,7 & 27 & 33,7 & 34 & 42,4 & \\
\hline Total & 32 & 40 & 48 & 60 & 80 & 100 & \\
\hline Dukungan Suami & 21 & 263 & 15 & 187 & 36 & 45 & 0005 \\
\hline
\end{tabular}


Journal of Healthcare Technology and Medicine Vol. 6 No. 2 Oktober 2020

Universitas Ubudiyah Indonesia

e-ISSN : 2615-109X

\begin{tabular}{ccccccc} 
Mendukung & 11 & 13,7 & 33 & 41,3 & 44 & 55 \\
\hline Total & $\mathbf{3 2}$ & $\mathbf{4 0}$ & $\mathbf{4 8}$ & $\mathbf{6 0}$ & $\mathbf{8 0}$ & $\mathbf{1 0 0}$ \\
\hline
\end{tabular}

\section{Sumber : Data Primer, 2019}

Berdasarkan Tabel 2. dapat dilihat bahwa dari 80 responden (100\%) terdapat 19 responden ibu hamil dengan umur yang beresiko di dapatkan $12(15 \%)$ tidak lengkap melakukan pemeriksaan ANC, sedangkan dari 61 responden ibu hamil dengan umur yang tidak beresiko didapatkan 41 (51,3\%) lengkap melakukan pemeriksaan ANC. Dari hasil uji statistik, chi-square diperoleh nilai kemaknaan $\mathrm{p}=0,036(<0,05)$, maka dapat di simpulkan bahwa ada pengaruh umur terhadap pemeriksaan ANC.

Pada variabel pendidikan dapat dilihat bahwa, dari 80 responden (100\%) terdapat 15 responden ibu hamil dengan pendidikan dasar di dapatkan 13 (16,3\%) tidak lengkap melakukan pemeriksaan ANC, dari 39 responden ibu hamil dengan pendidikan menengah di dapatkan 26 (33\%) lengkap melakukan pemeriksaan ANC, sedangkan dari 26 responden ibu hamil dengan pendidikan tinggi didapatkan 20 (25\%) lengkap melakukan pemeriksaan ANC. Dari hasil uji statistik, chi-square diperoleh nilai kemaknaan $\mathrm{p}=0,000(<0,05)$, maka dapat di simpulkan bahwa ada pengaruh pendidikan terhadap pemeriksaan ANC.

Pada variabel pekerjaan dapat dilihat bahwa, dari 80 responden (100\%) terdapat 43 responden ibu hamil yang tidak bekerja di dapatkan 23 (28,8\%) lengkap melakukan pemeriksaan ANC, sedangkan dari 37 responden ibu hamil yang bekerja didapatkan 25 (31,2 $\%)$ lengkap melakukan pemeriksaan ANC. Dari hasil uji statistik, chi-square diperoleh nilai kemaknaan $\mathrm{p}=0,292(>0,05)$, maka dapat di simpulkan bahwa tidak ada pengaruh pekerjaan terhadap pemeriksaan ANC.

Pada variabel pengetahuan dapat dilihat bahwa, dari 80 responden (100\%) terdapat 35 responden ibu hamil dengan pengetahuan yang kurang di dapatkan 20 (25\%) tidak lengkap melakukan pemeriksaan ANC, sedangkan dari 45 responden ibu hamil dengan pengetahuan yang baik didapatkan 33 (41,2 \%) lengkap melakukan pemeriksaan ANC. Dari hasil uji statistik, chi-square diperoleh nilai kemaknaan $\mathrm{p}=0,011(<0,05)$, maka dapat di simpulkan bahwa ada pengaruh pengetahuan terhadap pemeriksaan ANC.

Pada variabel paritas dapat dilihat bahwa, dari 80 responden (100\%) terdapat 37 responden ibu hamil dengan paritas primipara di dapatkan $23(28,8 \%)$ lengkap melakukan pemeriksaan ANC, sedangkan dari 43 responden ibu hamil dengan paritas multipara didapatkan 25 (31,2 \%) lengkap melakukan pemeriksaan ANC. Dari hasil uji statistik, chi- 
Journal of Healthcare Technology and Medicine Vol. 6 No. 2 Oktober 2020

Universitas Ubudiyah Indonesia

e-ISSN : 2615-109X

square diperoleh nilai kemaknaan $\mathrm{p}=0,891(>0,05)$, maka dapat di simpulkan bahwa tidak ada pengaruh paritas terhadap pemeriksaan ANC.

Pada variabel jarak tempat kesehatan dapat dilihat bahwa, dari 80 responden (100\%) terdapat 46 responden ibu hamil dengan jarak tempat kesehatan yang jauh di dapatkan 25 (31,3 $\%$ ) tidak lengkap melakukan pemeriksaan ANC, sedangkan dari 34 responden ibu hamil dengan jarak tempat kesehatan yang dekat didapatkan 27 (33,7\%) lengkap melakukan pemeriksaan ANC. Dari hasil uji statistik, chi-square diperoleh nilai kemaknaan $\mathrm{p}=0,005$ (< 0,05), maka dapat di simpulkan bahwa ada pengaruh jarak tempat kesehatan terhadap pemeriksaan ANC.

Pada variabel dukungan suami dapat dilihat bahwa, dari 80 responden $(100 \%)$ terdapat 36 responden ibu hamil yang tidak mendapat dukungan dari suami di dapatkan 21 (26,3\%) tidak lengkap melakukan pemeriksaan ANC, sedangkan dari 44 responden ibu hamil yang mendapat dukungan dari suami didapatkan 33 (41,3\%) lengkap melakukan pemeriksaan ANC. Dari hasil uji statistik, chi-square diperoleh nilai kemaknaan $\mathrm{p}=0,005(<0,05)$, maka dapat di simpulkan bahwa ada pengaruh dukungan suami terhadap pemeriksaan ANC.

Tabel 3

Tabel Hasil Analisis Regresi Logistik

\begin{tabular}{lcccc}
\hline \multicolumn{1}{c}{ Variabel Penelitian } & Df & Sig. & $\operatorname{Exp(B)}$ & $\begin{array}{c}\text { 95\% C.I.for } \\
\mathbf{E X P}(\mathbf{B})\end{array}$ \\
\hline Umur & 1 & 0,053 & 0,299 & $0,088-1,017$ \\
Jarak Tempat Kesehatan & 1 & 0,008 & 0,223 & $0,073-0,680$ \\
Dukungan Suami & 1 & 0,003 & 0,201 & $0,069-0,587$ \\
\hline
\end{tabular}

\section{Sumber, Data Primer 2019}

Hasil analisis penelitian diketahui bahwa seluruh variabel penelitian telah signifikan. Variabel tersebut antara lain faktor umur diperoleh nilai sig 0,053 , jarak tempat kesehatan diperoleh nilai sig 0,008, dan faktor dukungan suami diperoleh nilai sig 0,003. Dapat dilihat bahwa dukungan suami yang paling berpengaruh (dominan) terhadap Pemeriksaan ANC Pada Ibu Hamil Di Wilayah Kerja Puskesmas Kebayakan Kabupaten Aceh Tengah Provinsi Aceh Tahun 2019. Faktor dukungan suami dengan nilai $\operatorname{Exp}(B)$ 0,201 yang artinya bahwa ibu hamil yang mendapat dukungan dari suami 0,201 kali lebih besar memengaruhi pemeriksaan ANC dibandingkan dengan ibu hamil yang tidak mendapat dukungan suami.

\section{Pengaruh Umur Terhadap Pemeriksaan ANC Pada Ibu Hamil Di Wilayah Kerja Puskesmas Kebayakan}

Berdasarkan Tabel 2. dapat dilihat bahwa dari 80 responden (100\%) terdapat 19 responden ibu hamil dengan umur yang beresiko di dapatkan 12 (15\%) tidak lengkap 
Journal of Healthcare Technology and Medicine Vol. 6 No. 2 Oktober 2020

Universitas Ubudiyah Indonesia

e-ISSN : 2615-109X

melakukan pemeriksaan ANC, sedangkan dari 61 responden ibu hamil dengan umur yang tidak beresiko didapatkan 41 (51,3 \%) lengkap melakukan pemeriksaan ANC. Dari hasil uji statistik, chi-square diperoleh nilai kemaknaan $\mathrm{p}=0,036(<0,05)$, maka dapat di simpulkan bahwa ada pengaruh umur terhadap pemeriksaan ANC.

Penelitian ini juga sesuai dengan hasil penelitian Yulyani, menunjukkan bahwa sebagian besar ibu hamil di puskesmas Danurejan I adalah berumur 20-35 tahun (tidak beresiko), dengan persentase yang jauh lebih tinggi (76,7\%) dibandingkan dengan ibu hamil dalam kriteria umur beresiko ( $<20$ atau $>35$ tahun) (23,3\%). Hasil uji statistik diketahui p value $0.000<0,05$ berarti ada hubungan yang bermakna antara umur ibu dengan kunjungan $\mathrm{K} 4$, dengan $p$-value $=0,000(<\alpha=0,05)$ (Yulyani, 2017).

Secara kualitatif diketahui bahwa informan 1 memiliki umur 38 tahun dan informan 2 memiliki umur 34 tahun. Dari kedua informan tersebut, dapat dilihat bahwa informan 1 berada pada usia beresiko sedangkan informan 2 berada pada usia tidak beresiko.

Umur merupakan salah satu faktor penentu dalam proses kehamilan. Pada umur 20-35 cenderung lebih teratur karena masih merasa bahwa pemeriksaan kehamilan sangat penting sedangkan umur $<20$ tahun cenderung belum terlalu mengerti tentang pentingnya melakukan kunjungan antenatal secara teratur sedangkan umur $>35$ tahun cenderung acuh pada kunjungan antenatal karena merasa telah memiliki pengalaman yang baik padahal seharusnya kedua kelompok umur ini rutin memeriksakan kehamilan ke petugas kesehatan karena berisiko tinggi terhadap kehamilan dan persalinan. Usia berguna untuk mengantisipasi diagnosa masalah kesehatan dan tindakan yang dilakukan (Pongsibidang, 2013).

Menurut temuan peneliti ibu hamil dengan kategori umur tidak beresiko (20-35 tahun) lebih banyak dalam melakukan pemeriksaan ANC. Ibu yang tergolong usia 20-35 tahun memiliki kesiapan yang baik untuk hamil, dimana selama proses kehamilan diperlukan kematangan fisik, emosi maupun psikologi dari ibu hamil itu sendiri. Proses kehamilan perlu didukung oleh kesabaran, pemahaman dan juga keterampilan ibu dalam menjaga kehamilannya tetap berlangsung baik dan normal demi keselamatan dirinya dan juga janin yang dikandung. Berbeda dengan ibu yang hamil di usia <20 tahun, yang masih belum begitu matang secara fisik, emosi, maupun psikologi. Begitupun ibu hamil dengan usia >35 tahun yang sebenarnya sudah memiliki kematangan emosi maupun psikologi yang baik, namun karena pengalamannya yang dirasa cukup sering kali membuat ibu hamil tersebut lalai dalam melakukan pemeriksaan.

Pengaruh Pendidikan Terhadap Pemeriksaan ANC Pada Ibu Hamil di Wilayah Kerja Puskesmas Kebayakan Kabupaten Aceh Tengah 
Journal of Healthcare Technology and Medicine Vol. 6 No. 2 Oktober 2020

Universitas Ubudiyah Indonesia

e-ISSN : 2615-109X

Berdasarkan Tabel 2. dapat dilihat bahwa dari 80 responden (100\%) terdapat 15 responden ibu hamil dengan pendidikan dasar di dapatkan 13 (16,3 \%) tidak lengkap melakukan pemeriksaan ANC, dari 39 responden ibu hamil dengan pendidikan menengah di dapatkan 26 (33\%) lengkap melakukan pemeriksaan ANC, sedangkan dari 26 responden ibu hamil dengan pendidikan tinggi didapatkan 20 (25\%) lengkap melakukan pemeriksaan ANC. Dari hasil uji statistik, chi-square diperoleh nilai kemaknaan $\mathrm{p}=0,000(<0,05)$, maka dapat di simpulkan bahwa ada pengaruh pendidikan terhadap pemeriksaan ANC.

Hasil penelitian ini sejalan dengan penelitian Kurniasari, perhitungan analisis chi square terhadap hubungan pendidikan dengan status kunjungan kehamilan diperoleh nilai $\mathrm{p}$ value $=0,038$ lebih kecil dari alpha $(0,05)$ sehingga Ho di tolak dan Ha diterima. Maka secara statistik ada hubungan antara pendidikan dengan status kunjungan kehamilan. Secara statistik diperoleh Odds Ratio $(\mathrm{OR})=5,385$ yang berarti bahwa responden yang memiliki status pendidikan tinggi 5,385 kali lebih besar untuk memiliki status kunjungan kehamilan lengkap dibandingkan responden yang memiliki status pendidikan rendah di Puskesmas Kesumadadi Kabupaten Lampung Tengah Tahun 2016 (Kurniasari, 2016).

Menurut Lawrence Green dalam Notoatmodjo, menyatakan pendidikan merupakan faktor predisposisi yang cukup penting dalam mempengaruhi perilaku seseorang. Pendidikan seseorang sangat berpengaruh terhadap perilaku individu dalam mengambil setiap keputusan dan sikapnya yang selalu berpedoman pada apa yang mereka dapatkan melalui proses belajar dan pengalaman yang diterimanya (Notoatmodjo, 2010). Menurut Langefielt dalam Walgito, semakin tinggi tingkat pendidikan maka cara pandang orang tersebut terhadap segala sesuatu kehidupan masyarakat akan lebih luas. Semakin dewasa seseorang maka sikapnya terhadap sesuatu yang dianggapnya bermanfaat akan lebih rasional (Walgito, 2010).

Secara kualitatif diketahui bahwa informan 1 pendidikan terakhirnya adalah D2 Pendidikan Agama Islam dan informan 2 pendidikan terakhirnya adalah SMA. Dari kedua informan tersebut, dapat dilihat bahwa informan 1 memiliki pendidikan tinggi sedangkan informan 2 memiliki pendidikan menengah.

Menurut temuan peneliti ibu hamil dengan pendidikan menengah lebih lengkap melakukan pemeriksaan ANC dibandingkan dengan ibu hamil yang berpendidikan tinggi. Ibu hamil dengan pendidikan tinggi mempunyai motivasi tinggi untuk melakukan pemeriksaan ANC secara rutin selama masa kehamilan. Dengan tingginya pendidikan ibu hamil semakin bertambah pengetahuan yang didapatkan khususnya pengetahuan tentang kehamilan. Semakin banyak pengetahuan ibu terhadap komplikasi yang akan terjadi pada masa kehamilan maka ibu 
Journal of Healthcare Technology and Medicine Vol. 6 No. 2 Oktober 2020

Universitas Ubudiyah Indonesia

e-ISSN : 2615-109X

cepat mewaspadai terhadap kehamilannya. Sedangkan ibu yang berpendidikan rendah akan berdampak pada rendahnya pengetahuan yang berpengaruh pada keputusan ibu untuk mendapatkan pelayanan kesehatan. Walaupun demikian, tidak berarti bahwa ibu hamil dengan pendidikan menengah tidak lengkap melakukan pemeriksaan ANC.

\section{Pengaruh Pekerjaan Terhadap Pemeriksaan ANC Pada Ibu Hamil Di Wilayah Kerja Puskesmas Kebayakan Kabupaten Aceh Tengah}

Berdasarkan Tabel 2. dapat dilihat bahwa dari 80 responden (100\%) terdapat 43 responden ibu hamil yang tidak bekerja di dapatkan 23 (28,8\%) lengkap melakukan pemeriksaan ANC, sedangkan dari 37 responden ibu hamil yang bekerja didapatkan 25 (31,2 $\%)$ lengkap melakukan pemeriksaan ANC. Dari hasil uji statistik, chi-square diperoleh nilai kemaknaan $\mathrm{p}=0,292(>0,05)$, maka dapat di simpulkan bahwa tidak ada pengaruh pekerjaan terhadap pemeriksaan ANC.

Hasil penelitian yang sama dijelaskan Pongsibidang yang menyatakan bahwa, tidak ada hubungan antara pekerjaan ibu untuk melakukan kunjungan antenatal. Ibu yang bekerja sebagai PNS atau pegawai/karyawan swasta lebih teratur melakukan kunjungan antenatal dibandingkan ibu yang bekerja sebagai pedagang atau wiraswasta dan ibu rumah tangga. Penyebabnya adalah ibu yang berkerja sebagai pegawai negeri atau pegawai/karyawan swasta mempunyai pendidikan yang tinggi serta pengetahuan yang cukup dibandingkan dengan ibu yang bekerja sebagai pedagang/wiraswasta dan ibu rumah tangga (Pongsibidang, 2013).

Hasil penelitian ini tidak sejalan dengan teori yang menyatakan bahwa Pekerjaan ibu yang dimaksudkan adalah apabila ibu beraktifitas ke luar rumah maupun di dalam rumah kecuali pekerjaan rutin rumah tangga. Ibu yang bekerja akan memiliki sedikit waktu untuk memeriksakan kehamilannya dan lebih banyak menghabiskan waktu untuk bekerja. Sedangkan ibu yang tidak bekerja, akan memiliki banyak waktu untuk memeriksakan kehamilan (Notoatmodjo, 2010).

Secara kualitatif diketahui bahwa pekerjaan informan 1 adalah guru honorer dan pekerjaan informan 2 adalah ibu rumah tangga (IRT). Dari kedua informan tersebut dapat dilihat bahwa informan 1 bekerja sebagai guru honorer sedangkan informan 2 tidak bekerja hanya sebagai ibu rumah tangga.

Menurut temuan peneliti tidak ada pengaruh pekerjaan terhadap pemeriksaan ANC, ibu hamil yang bekerja dan tidak bekerja tetap melakukan pemeriksaan ANC. Hal ini mungkin saja karena ibu hamil yang bekerja maupun tidak bekerja memiliki pengetahuan yang baik tentang 
Journal of Healthcare Technology and Medicine Vol. 6 No. 2 Oktober 2020

Universitas Ubudiyah Indonesia

e-ISSN : 2615-109X

pentingnya pemeriksaan kehamilan, sehingga disela-sela kesibukannya, ibu hamil tesebut tetap menyisihkan waktu untuk melakukan pemeriksaan kehamilan.

\section{Pengaruh Pengetahuan Terhadap Pemeriksaan ANC Pada Ibu Hamil Di Wilayah Kerja Puskesmas Kebayakan Kabupaten Aceh Tengah}

Berdasarkan Tabel 2. dapat dilihat bahwa dari 80 responden (100\%) terdapat 35 responden ibu hamil dengan pengetahuan yang kurang di dapatkan 20 (25\%) tidak lengkap melakukan pemeriksaan ANC, sedangkan dari 45 responden ibu hamil dengan pengetahuan yang baik didapatkan 33 (41,2 \%) lengkap melakukan pemeriksaan ANC. Dari hasil uji statistik, chi-square diperoleh nilai kemaknaan $\mathrm{p}=0,011(<0,05)$, maka dapat di simpulkan bahwa ada pengaruh pengetahuan terhadap pemeriksaan ANC.

Hasil penelitian ini sejalan dengan penelitian Dewie, hasil uji statistic didapatkan nilai $\mathrm{p}$ value $=0,009(<\alpha=0,05)$ yang berarti bahwa ada hubungan yang signifikan antara pengetahuan dengan kunjungan K4. Ini berarti bahwa dengan pengetahuan yang baik, maka ibu hamil akan rutin untuk melakukan pemeriksaan kehamilan, dalam hal ini adalah kunjungan K4 (Dewie, 2016).

Pengetahuan mempunyai peranan sebagai motivasi awal bagi seseorang dalam berperilaku. Namun demikian, perubahan pengetahuan tidak selamanya dapat menyebabkan perubahan perilaku. Menurut Lawrence Green dalam Notoatmodjo menyebutkan pengetahuan merupakan salah satu faktor predisposing terhadap pembentukan perilaku seseorang. Pengetahuan merupakan domain yang sangat penting dalam membentuk tindakan seseorang (overt behavior) dan pengetahuan memegang penting dalam menentukan sikap, karena itu pengetahuan yang dimiliki ibu mempunyai pengaruh terhadap tindakan pemeriksaan kehamilan (Notoatmodjo, 2010).

Menurut temuan peneliti ibu dengan pengetahuan yang tinggi akan memiliki kesadaran dan keinginan untuk memeriksakan kehamilannya. Pengetahuan tentang pentingnya pemeriksaan kehamilan yang dimiliki oleh ibu hamil mempengaruhi perilaku ibu dalam melakukan pemeriksaan ANC sehingga bahaya kehamilan dapat dihindari. Dengan pengetahuan yang dimilikinya, maka ibu akan mempunyai kesadaran untuk melakukan pemeriksaan ANC dengan lengkap.

\section{Pengaruh Paritas Terhadap Pemeriksaan ANC Pada Ibu Hamil Di Wilayah Kerja Puskesmas Kebayakan Kabupaten Aceh Tengah}

Berdasarkan Tabel 2. dapat dilihat bahwa dari 80 responden (100\%) terdapat 37 responden ibu hamil dengan paritas primipara di dapatkan $23(28,8 \%)$ lengkap melakukan 
Journal of Healthcare Technology and Medicine Vol. 6 No. 2 Oktober 2020

Universitas Ubudiyah Indonesia

e-ISSN : 2615-109X

pemeriksaan ANC, sedangkan dari 43 responden ibu hamil dengan paritas multipara didapatkan 25 (31,2 \%) lengkap melakukan pemeriksaan ANC. Dari hasil uji statistik, chi square diperoleh nilai kemaknaan $\mathrm{p}=0,891(>0,05)$, maka dapat di simpulkan bahwa tidak ada pengaruh paritas terhadap pemeriksaan ANC.

Hasil penelitian ini sejalan dengan penelitian Chorunnisa (2018), hasil uji statistic didapatkan nilai p value $=0,540(>\alpha=0,05)$ yang berarti bahwa tidak ada hubungan antara paritas dengan pemeriksaan K4 pada ibu hamil. Hasil penelitian ini sejalan dengan Pongsibidang yang menyatakan bahwa tidak ada hubungan antara paritas ibu dengan keteraturan kunjungan kehamilan. Ibu dengan paritas tinggi lebih merasa dirinya sudah berpengalaman dalam kehamilan dan persalinan, sehingga tidak terlalu khawatir lagi seperti pada saat kehamilan sebelumnya (Pongsibidang, 2013).

Hasil penelitian ini tidak sejalan dengan teori yang menyatakan bahwa Ibu hamil primigravida lebih ingin kehamilanya selalu dalam keadaan baik dan sehat karena belum mempunyai pengalaman tentang kehamilan sehingga dalam perjalanan kehamilan dan menuju persalinan selalu menjaga kehamilan supaya aman dan nyaman. Ibu hamil dengan jumlah anak lebih sedikit cenderung akan lebih baik dalam memeriksakan kehamilannya daripada ibu hamil dengan jumlah anak lebih banyak (Winkjosastro, 2005).

Secara kualitatif diketahui bahwa informan 1 memiliki paritas primipara yaitu informan sudah pernah melahirkan anak satu kali dan informan 2 memiliki paritas multipara yaitu informan sudah pernah melahirkan anak sebanyak 3 kali.

Menurut temuan peneliti Ibu dengan paritas multipara atau primipara berpeluang sama dan tidak berpengaruh terhadap kelengkapan pemeriksaan kehamilannya, karna ibu dengan paritas multipara yang mempunyai risiko pada kehamilaan sebelumnya, dia merasa perlu untuk memeriksakan kehamilannya, begitu pula ibu dengan paritas primiprara merasa perlu untuk memeriksakan kehamilan secara teratur karena belum memiliki pengalaman tentang kehamilan. Sebaliknya dapat pula, ibu yang kurang memanfaatkan pelayanan antenatal dengan paritas multipara merasa telah memiliki pengalaman pada kehamilan sebelumnya sehingga tidak perlu sering memeriksakan kehamilan dan ibu dengan paritas primipara yang kurang memeriksakan kehamilan disebabkan karena terlambat mengetahui tentang kehamilannya.

\section{Pengaruh Jarak Tempat Kesehatan Terhadap Pemeriksaan ANC Pada Ibu Hamil Di Wilayah Kerja Puskesmas Kebayakan Kabupaten Aceh Tengah}

Berdasarkan Tabel 2. dapat dilihat bahwa dari 80 responden (100\%) terdapat 46 responden ibu hamil dengan jarak tempat kesehatan yang jauh di dapatkan 25 (31,3\%) tidak 
Journal of Healthcare Technology and Medicine Vol. 6 No. 2 Oktober 2020

Universitas Ubudiyah Indonesia

e-ISSN : 2615-109X

lengkap melakukan pemeriksaan ANC, sedangkan dari 34 responden ibu hamil dengan jarak tempat kesehatan yang dekat didapatkan $27(33,7 \%)$ lengkap melakukan pemeriksaan ANC. Dari hasil uji statistik, chi-square diperoleh nilai kemaknaan $p=0,005(<0,05)$, maka dapat di simpulkan bahwa ada pengaruh jarak tempat kesehatan terhadap pemeriksaan ANC.

Hasil penelitian ini sejalan dengan penelitian Erlina, hasil uji statistic didapatkan nilai $\mathrm{p}$ value $=0,011(<\alpha=0,05)$ yang berarti bahwa terdapat hubungan yang bermakna antara keterjangkauan terhadap kunjungan pemeriksaan kehamilan. Keterjangkauan pelayanan kesehatan mencakup jarak, waktu dan biaya. Tempat pelayanan yang lokasinya tidak strategis atau sulit dicapai oleh para ibu menyebabkan berkurangnya akses ibu hamil terhadap pelayanan kesehatan. Walaupun ketersediaan pelayanan kesehatan sudah memadai, namun penggunaannya tergantung dari aksesibilitas masyarakat terhadap informasi (Rahma, 2013).

Semakin jauh jarak fasilitas kesehatan dari tempat tinggal ibu hamil serta semakin sulit akses menuju ke fasilitas kesehatan akan menurunkan motivasi ibu hamil untuk melakukan kunjungan ANC. Jauhnya jarak akan membuat ibu berfikir dua kali untuk melakukan kunjungan karena akan memakan banyak tenaga dan waktu setiap melakukan kunjungan. Ibu yang tidak menggunakan transportasi dan harus berjalan kaki menuju ke tempat pelayanan kesehatan mayoritas memiliki angka kunjungan kurang dari 4 kali selama masa kehamilan (Rachmawati, 2017).

Secara kualitatif diketahui bahwa jarak rumah informan 1 dekat dengan tempat pelayanan kesehatan dan ibu juga tidak membutuhkan alat transportasi untuk sampai ke tempat kesehatan, sedangkan jarak rumah informan 2 jauh dengan tempat pelayanan kesehatan dan membutuhkan alat transportasi hingga bisa sampai ke tempat pelayanan kesehatan tersebut.

Menurut temuan peneliti ibu hamil dengan jarak tempat kesehatan yang dekat lebih lengkap melakukan pemeriksaan ANC dibandingkan ibu dengan jarak yang jauh. Semakin jauh jarak yang harus ditempuh ibu hamil untuk melakukan pemeriksaan ANC maka akan semakin kecil pula kesempatan yang dimiliki ibu hamil dalam melakukan pemeriksaan ANC. Jauhnya jarak akan membuat ibu berfikir dua kali untuk melakukan kunjungan karena akan memakan banyak tenaga dan waktu setiap melakukan kunjungan.

\section{Pengaruh Dukungan Suami Terhadap Pemeriksaan ANC Pada Ibu Hamil Di Wilayah Kerja Puskesmas Kebayakan Kabupaten Aceh Tengah}

Berdasarkan Tabel 2. dapat dilihat bahwa dari 80 responden (100\%) terdapat 36 responden ibu hamil yang tidak mendapat dukungan dari suami di dapatkan 21 (26,3\%) tidak lengkap melakukan pemeriksaan ANC, sedangkan dari 44 responden ibu hamil yang mendapat 
Journal of Healthcare Technology and Medicine Vol. 6 No. 2 Oktober 2020

Universitas Ubudiyah Indonesia

e-ISSN : 2615-109X

dukungan dari suami didapatkan 33 (41,3\%) lengkap melakukan pemeriksaan ANC. Dari hasil uji statistik, chi-square diperoleh nilai kemaknaan $\mathrm{p}=0,005(<0,05)$, maka dapat di simpulkan bahwa ada pengaruh dukungan suami terhadap pemeriksaan ANC.

Hasil penelitian ini sesuai dengan penelitian Sari, dukungan suami negatif sebagian besar responden tidak teratur dalam melakukan kunjungan antenatal care yaitu sebanyak 17 responden $(51,5 \%)$ dan untuk dukungan suami positif seluruhnya teratur melakukan kunjungan antenatal care yaitu sebanyak 6 responden (18,2\%). Dari hasil uji chi-square dengan tingkat kemaknaan $\alpha(0,05)$ didapatkan nilai signifikasi sebesar 0,005 yang berarti dukungan suami dalam pelaksanaan antenatal care memiliki pengaruh terhadap kunjungan antenatal care pada ibu hamil (Sari, 2013).

Hasil penelitian diatas juga sesuai dengan teori Green dalam Notoadmojo bahwa dukungan adalah dukungan yang diberikan oleh suami pada istrinya yang sedang hamil dalam hal ini dukungan tersebut bisa dalam bentuk verbal atau non verbal, saran, bantuan yang nyata berupa tingkah laku atau kehadiran yang dapat memberikan keuntungan emosional dan mempengaruhi tingkah laku istrinya yang dalam hal ini adalah dukungan untuk melakukan kunjungan ANC. Suami merupakan bagian dari keluarga, maka dukungan suami sangat diperlukan dalam menentukan berbagai kebijakan dalam keluarga. Dukungan merupakan salah satu faktor penguat (reinforcing factor) yang dapat mempengaruhi seseorang dalam berperilaku (Notoatmodjo, 2010).

Secara kualitatif diketahui bahwa informan 1 tidak pernah diantar oleh suaminya saat periksa hamil, itu disebabkan karena suami sibuk bekerja, adapun dukungan lain yang diberikan adalah menjaga kesehatan dan menjaga pola makan ibu selama hamil. Sedangkan informan 2 juga mengatakan tidak pernah diantar oleh suaminya saat periksa hamil karena bapak sibuk bekerja.

Menurut temuan peneliti ibu hamil yang mendapat dukungan dari suami lebih lengkap melakukan pemeriksaan ANC dibandingkan dengan ibu yang tidak mendapat dukungan. Dukungan suami dapat meningkatkan minat dan motivasi ibu untuk memanfaatkan pelayanan kesehatan sehingga ibu melakukan pemeriksaan kehamilan secara rutin selama kehamilan. Keterlibatan suami sejak awal kehamilan sampai dengan persalinan dan nifas akan meningkatkan perilaku perawatan ibu hamil sehingga menentukan keberhasilan ibu dalam masa kehamilan sampai dengan proses persalinan.

\section{KESIMPULAN}


Journal of Healthcare Technology and Medicine Vol. 6 No. 2 Oktober 2020

Universitas Ubudiyah Indonesia

e-ISSN : 2615-109X

Kesimpulan dalam penelitian ini adalah ada pengaruh umur, pendidikan, pengetahuan, jarak tempat kesehatan, dukungan suami dengan pemeriksaan ANC dan tidak ada pengaruh pendidikan dan paritas dengan pemeriksaan ANC di wilayah kerja Puskesmas Kebayakan Kabupaten Aceh Tengah Tahun 2019. Adapun variabel yang paling berpengaruh terhadap pemeriksaan ANC adalah dukungan suami. Diharapkan bidan dan tenaga kesehatan lainnya meningkatkan upaya promotif tentang pentingnya pemeriksaan ANC kepada masyarakat sehingga pengetahuan masyarakat khususnya ibu hamil menjadi meningkat mengenai pentingnya melakukan pemeriksaan ANC.

\section{SARAN}

1. Bagi ibu hamil

a. Ibu hamil yang sudah mengetahui dan memahami pentingnya melakukan pemeriksaan ANC secara lengkap, maka harus mempertahankan sikap dan perilaku sehatnya selama kehamilan maupun pada kehamilan selanjutnya.

2. Bagi Puskesmas

a. Disarankan kepada tenaga kesehatan di Puskesmas khususnya Bidan untuk meningkatkan konseling dan penyuluhan yang lebih intensif mengenai pentingnya pemeriksaan kehamilan secara rutin serta lebih memotivasi kepada ibu-ibu hamil agar lebih rutin untuk memeriksakan kehamilannya minimal empat kali selama masa kehamilan agar kondisi kesehatan ibu dan janin tetap terjaga.

b. Melakukan upaya kunjungan rumah bagi ibu hamil yang tidak lengkap memeriksakan kehamilannya, dengan melibatkan kerjasama para tokoh masyarakat seperti RW, RT dan para kader di setiap desa agar pencapaian target dapat dipenuhi.

3. Bagi peneliti selanjutnya

a. Peneliti lain dapat menjadikan data pada penelitian ini sebagai data dasar bagi penelitiannya. Peneliti lain disarankan menambah variabel faktor predisposisi, faktor pemungkin, dan faktor penguat yang lain terhadap ibu melakukan pemeriksaan ANC sehingga dapat diketahui faktor yang paling mempengaruhi keteraturan ibu hamil melakukan ANC. 
Journal of Healthcare Technology and Medicine Vol. 6 No. 2 Oktober 2020

Universitas Ubudiyah Indonesia

e-ISSN : 2615-109X

b. Peneliti lain disarankan melakukan penelitian di tempat lain yang memiliki kunjungan ANC rendah dengan metode atau desain yang berbeda, dan jumlah responden yang lebih besar.

4. Bagi Masyarakat

a. Disarankan pada masyarakat agar ikut aktif hadir atau berperan serta apabila ada kegiatan penyuluhan yang diselenggarakan oleh tenaga kesehatan dari Puskesmas khususnya penyuluhan tentang pemeriksaan kehamilan

b. Untuk suami atau keluarga agar memberikan dukungan terhadap ibu yang sedang hamil dengan cara mengantar, mengingatkan ibu untuk memeriksakan kehamilannya sampai dengan lengkap serta menanyakan hasil dari pemeriksaan kehamilannya.

\section{DAFTAR PUSTAKA}

Choirunissa, R., dan Syaputri, N. D. (2018). Analisis Faktor yang Berhubungan Dengan Pemeriksaan K4 Pada Ibu Hamil di Puskesmas Bakung Provinsi Lampung Tahun 2017. Akad Keperawatan Husada Karya Jaya. 4:72-93. Diakses di : ejurnal.husadakaryajaya.ac.id

Dewie, A. (2017). Faktor-Faktor yang Mempengaruhi Kunjungan K4 di Puskesmas Baqa Kota Samarinda Tahun 2016. Ilmu Kesehatan Diagnosis. 10:239-43.

Dinkes Aceh. (2018). Profil Kesehatan Aceh Tahun 2017. Diakses di : www.dinkes.acehprov.go.id

Kementerian Kesehatan RI. (2018). Profil Kesehatan Indonesia Tahun 2017. Jakarta. Diakses di : depkes.go.id

Khasanah, F. (2017). Gambaran Kunjungan Antenatal Care Di Puskesmas Pondok Jagung Kota Tangerang Selatan. Diakses di : repository.uinjkt.ac.id

Kurniasari, D. (2016). Faktor-faktor yang Mempengaruhi Kunjungan Kehamilan di Puskesmas Kesumadadi Kabupaten Lampung Tengah Tahun 2016. Kebidanan. 2(4):159-68. Diakses di : ejurnalmalahayati.ac.id

Notoatmodjo, S. (2010). Ilmu Perilaku Kesehatan. Jakarta: Rineka Cipta.

Prawirohardjo, S. (2010). Ilmu Kebidanan. Jakarta: Bina Pustaka

Profil Kesehatan Kabupaten Aceh Tengah Tahun 2016. takengon, aceh tengah; 2017. Diakses di : depkes.go.id

Profil Kesehatan Kabupaten Aceh Tengah Tahun 2017. takengon, aceh tengah; 2018. Diakses di : depkes.go.id

Pongsibidang, G. S. (2013). Faktor yang Berhubungan dengan Keteraturan Kunjungan Antenatal di Wilayah Kerja Puskesmas Kapala Pitu Kabupaten Toraja Utara. 1-13. 
Journal of Healthcare Technology and Medicine Vol. 6 No. 2 Oktober 2020

Universitas Ubudiyah Indonesia

e-ISSN : 2615-109X

Diakses di : repository.unhas.ac.id

Rachmawati, A. I. (2017). Faktor-faktor yang Memengaruhi Kunjungan Antenatal Care (ANC) Ibu Hamil. Majority. 7(November):72-6.

Rahma, E. (2013). Faktor-Faktor yang Mempengaruhi Ibu Hamil Terhadap Kunjungan Pemeriksaan Kehamilan di Puskesmas Rawat Inap Panjang Bandar Lampung. Med J Lampung Univ. 2(4):29-34.

Sari, K., I. P. (2013). Analisis Faktor yang Berpengaruh Terhadap Kunjungan Antenatal Care. Keperawatan dan Kebidanan. 93-113.

Walgito, B. (2010). Pengantar Psikologi Umum. Yogyakarta: Andi Offset

Winkjosastro, H. (2005). Ilmu Kebidanan. Jakarta: Yayasan Bina Pustaka

Yulyani, L. (2017). Faktor-faktor yang Berhubungan dengan Kunjungan K4 Pada Ibu Hamil di Puskesmas Danurejan 1 Kota Yogyakarta. Diakses di : digilib.unisayogya.ac.id 